\title{
Understanding Situated Social Interactions: A Case Study of Public Places in the City
}

\author{
J. Paay ${ }^{1,2} \&$ J. Kjeldskov ${ }^{2}$ \\ ${ }^{1}$ Interaction Design Group, Department of Information Systems, The University of Melbourne, \\ Victoria 3010, Australia; ${ }^{2}$ HCI Research Group, Department of Computer Science, \\ Aalborg University, Selma Lagerlöfs Vej 300, DK-9220 Aalborg East, Denmark \\ (E-mail: jeni@cs.aau.dk; jesper@cs.aau.dk)
}

\begin{abstract}
Ubiquitous and mobile computer technologies are increasingly being appropriated to facilitate people's social life outside the work domain. Designing such social and collaborative technologies requires an understanding of peoples' physical and social context, and the interplay between these and their situated interactions. In response, this paper addresses the challenge of informing design of mobile services for fostering social connections by using the concept of place for studying and understanding peoples' social activities in a public built environment. We present a case study of social experience of a physical place providing an understanding of peoples' situated social interactions in public places of the city derived through a grounded analysis of small groups of friends socialising out on the town. Informed by this, we describe the design and evaluation of a mobile prototype system facilitating sociality in the city by (1) allowing people to share places, (2) indexing to places, and (3) augmenting places.
\end{abstract}

Key words: augmenting the city, mobile computing, context-awareness, built environment, situated social interactions

\section{Introduction}

Mobile and ubiquitous computer technologies are increasingly being appropriated to facilitate people's social life outside the work domain linking people to people to places (Jones et al. 2004). Mobile phones, and especially SMS texting, have changed the way people communicate, interact in the physical world, and coordinate their social activities (Grinter and Eldridge 2001; Rheingold 2003). By embedding networked sensors into the built environment, adding advanced positioning technology and short range network capabilities (such as Bluetooth, RFID tags, etc.), context-aware mobile services are emerging that adapt their content to both the user's physical and social context.

When designing mobile services for fostering social connections and augmenting our physical built environment, system developers and interaction designers are faced with a series of new challenges. We need to understand better the physical and social context of the user's situated social interactions (McCullough 2004), the role of human activity within the built environment 
(Ciolfi 2004) and the interplay between context and user actions (Dourish 2004). We also need to understand how physical and social affordances of a place influence the situated interactions that occur there, including the relationship between people, technology and interactions. Finally, we need to define useful and understandable ways of incorporating peoples' physical and social context in interaction design for context-aware mobile services.

Recent work in human-computer interaction ( $\mathrm{HCI})$, computer-supported cooperative work $(\mathrm{CSCW})$ and interaction design has examined how the concept of place can contribute to our understanding of peoples' interactions within their physical environments and with ubiquitous computing technologies augmenting this environment, and how the notion of place can inform system and interaction design.

This paper addresses the challenge of informing ubiquitous and mobile technology design by using the concept of place as a central notion for studying and understanding peoples' social activities in a public built environment. We present a case study of social experience of a physical place providing an understanding of peoples' situated social interactions in public places of the city derived from a grounded analysis of small groups of friends socialising out on the town. Informed by this, we describe the design and evaluation of a context-aware prototype system facilitating sociality in the city by (1) allowing people to share places, (2) indexing to places, and (3) augmenting places.

The paper is structured in the following way. "Background" discusses related work focusing on people, technology and interactions in place. It presents and discusses our understanding of place, ubiquitous technology use in city contexts, and introduces the concept and typology of situated interactions. In "Field study: people socialising in a public place" we present our field study of people socialising in public places, describing the details of our empirical method and data analysis. In "Situated social interactions in public places" we present the findings from our study of situated social interactions in public places. To illustrate the value of understanding social interactions in place for informing interaction design of mobile services, "Designing for situated social interactions in public places" describes the design and evaluation of an implemented prototype system, which adapts to the user's physical and social context to foster social connections in that place. "Conclusions" concludes on our study.

\section{Background}

\subsection{People in place}

The design of the city affects how people make sense of the social complexities of urban places. The architectural design of form in the built environment has traditionally occurred within the context of an explicit set of social and physical issues in respect of anticipated activities and historical expectations tied to particular institutions and building types (Agre 2001; Mitchell 1995). Physical and social affordances of a place have helped to define the social interactions that 
occur there (Gaver 1996). Physical space plays a constructive as well as a receptive role in shaping social interaction in urban places (Hillier and Netto 2002). Space is given significance and becomes place through its link to human activity. We are located in space, but we act in place. Our shared understanding of the physical world helps people in presenting and interpreting activity and behaviour (Harrison and Dourish 1996). The physical and social layers of a space form the context of interaction for its inhabitants, intimately connected to their activities (Donath 1996). Accumulated experience helps people to identify with a place and in turn gain an understanding of what is going on in that place. Understanding the context of social interactions is an important part of designing ubiquitous computing that delivers information to people in the places and activities of their daily life (Agre 2001).

\subsection{Technology in place}

Architectural ideas about the nature of place are being challenged as communication and computation devices begin to saturate the built environment (Rheingold 2003). Ubiquitous computing is breaking down the traditional mapping between activities and place, allowing people to participate in social interactions that are no longer tied to their current location by supporting continual presence in every place (Agre 2001). For example, cafés become corporate meeting rooms as users deal with business calls over lunch, without any changes to the physical fabric of a place. Technology is uncoupling the close relationship between activities and place previously imposed by architectural design allowing social interactions to extend beyond a person's current physical location. Places no longer define appropriate activities by their physical design alone: now every place can be for everything, all of the time (Agre 2001; Mitchell 2003).

Understanding how to design ubiquitous computing that meshes with human behaviour and the properties of place that structure human interaction is immensely important (Ciolfi 2004; Erickson 1993). People who are digitally connected to each other and to the elements of the city use that technology to deliver information that is "just in time" and "just in place", to guide them to where they want to go and inform them about possible activities. This digital layer not only helps to structure our social interactions, but also provides a social medium for facilitating and enriching every day interactions between individuals (Erickson 1993).

Mobile services are increasingly becoming a part of the way we operate in urban places. Context-aware mobile information systems provide access to contextually adapted information and can foster social connections by sensing and responding to groups of co-located people in a place. In essence, they are connected to and respond to the place in which they are operating. The design of context-aware mobile information systems covers a broad spectrum of application areas, many of these mobile information systems involve the user being situated 
in urban public places, and yet only a few have investigated the challenges imposed and the opportunities offered through a grounded understanding of the relationship between activity and place.

\subsection{Interactions in place}

Studying people's "everyday action" can provide designers with a sense of the meaning associated with user activities, knowledge about what they actually do in a particular situation, and an understanding of people's experience of place. As Ciolfi (2004, p. 39) says, "understanding the dynamics of interaction in a space can help us design more effective systems in responding to behaviour and to changes in the environment."

McCullough (2004) approaches this problem with the idea of using typology (the study of recurrent forms) as a design philosophy to provide types of everyday situations as a way of abstracting an understanding of the influence of place on interaction. Using typology as a design philosophy provides a framework for creativity, allowing design to be based on themes rather than arbitrary innovation. It acknowledges existing living patterns of an inhabited place and helps designers of digital technology to recognise situated interactions and make technology a simpler, more adaptive and more social part of those interactions. McCullough asserts that place becomes reconfigured by ubiquitous computing not replaced by it, and that technology then extends the living patterns of that place. This approach to information technology design focuses on the need to understand how people interact in place. Gaining that understanding can be used to facilitate human-centred design of mobile services for fostering social connections.

A rudimentary typology of 30 everyday situations that may be transformed by technologies is proposed by McCullough (2004). This typology classifies situational types, grouped to reflect the following categories of place: workplace, dwelling place, the "third place" for conviviality, and the "fourth place" of commuting and travel. By using this typology as an analytical lens in this study, the concept of place becomes an organising theme for the data collected. This also limits the focus of the fieldwork to a manageable range of recognisable situations, allowing for design variations to benefit from being based on a few appropriate themes (McCullough). As derived from McCullough, the situated interactions associated with places for conviviality, that is, being out "on the town" are: places for socializing, places to meet, places for seeing and being seen, places for insiders, places for recreational retailing, places for embodied play, places for cultural productions, and places for ritual.

\section{Field study: people socialising in a public place}

Exploring the interplay between people, activity and place, we conducted an empirical field study of situated social interactions in the city. This study 
investigated the use of McCullough's (2004) typology of "on the town" everyday situations to guide fieldwork for informing interaction design of a mobile information system for a public place. The field study took place at Federation Square, Melbourne, Australia (Figure 1). Federation Square is a new civic structure covering an entire city block, providing the people of Melbourne with places for a variety of activities including restaurants, cafés, bars, a museum, galleries, cinemas, retail shops and several public forums.

\subsection{Participants, procedure and data collection}

The field study was conducted on location at Federation Square using the rapid ethnography method (Millen 2000). McCullough's (2004) typology focused the research scope at the beginning of the fieldwork by suggesting places for observations, and contextual interviews (Beyer and Holtzblatt 1998) facilitated interactive observation. Three different established social groups participated in the study as key informants. Each group consisted of three young urban people, mixed gender, between the ages of 20 and 35, who had a shared history of socialising at Federation Square. Each group met at Federation Square where they were not given any specific tasks but were asked to simply undertake the same

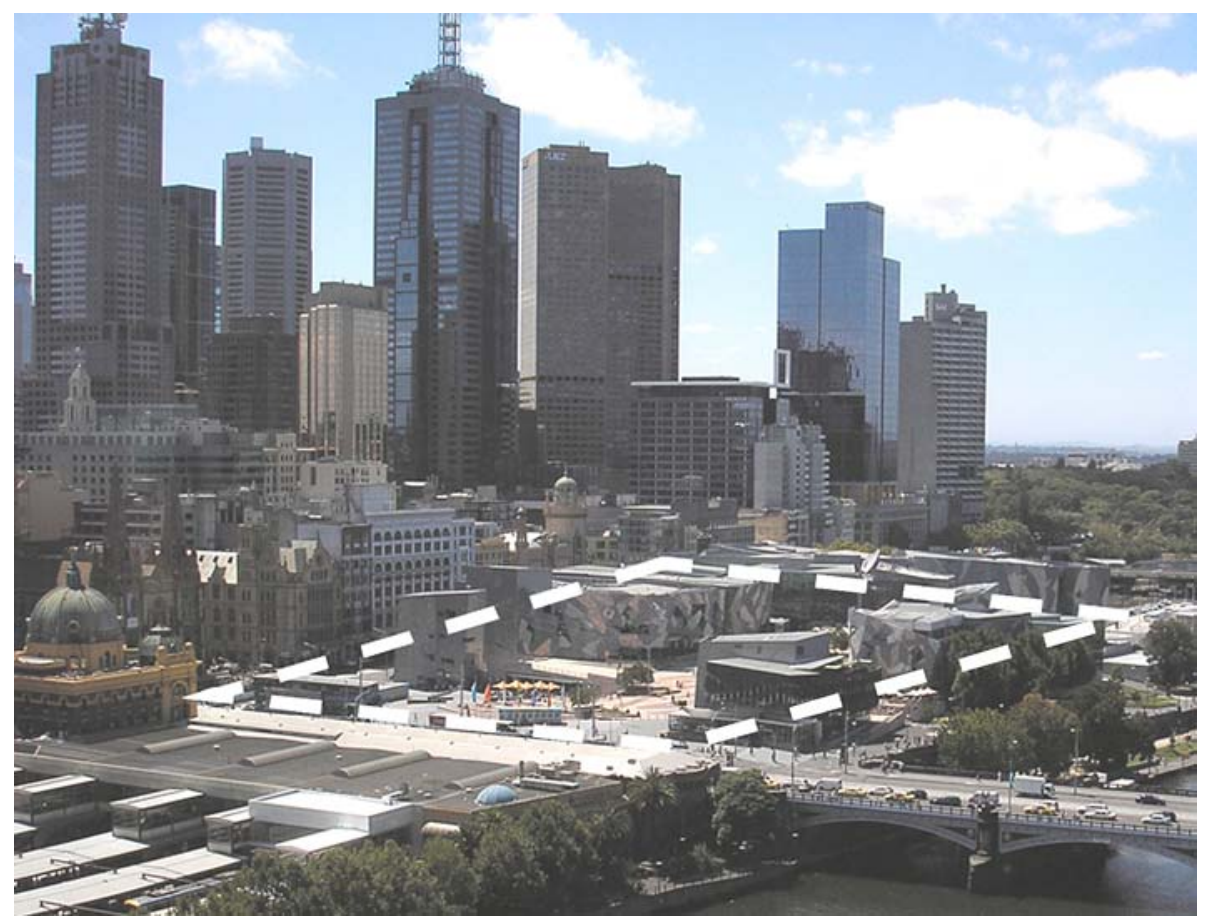

Figure 1. Federation Square, Melbourne, Australia, with surrounding skyline and river. 
activities that they would usually do as a group when socialising in the city. Each contextual interview and observation lasted approximately three hours (Figure 2). Digital video was used to document all questions, responses, activities and movement of the group around the square.

\subsection{Transcriptions and data analysis}

Shortly after the field visits all recordings were reviewed and situated interactions transcribed. The analysis of the transcript involved open and axial coding adapted from the grounded theory method (Strauss and Corbin 1990) chosen for its structured bottom up approach to analysing data to generate themes, and affinity diagramming (Beyer and Holtzblatt 1998) as a method for hierarchical grouping of themes (Figure 3). Grounded theory analysis produced 107 novel themes describing interactions and their relationship to place and activity. The affinity diagram refined these to a small set of high-level concepts, representing the essence of the data and encompassing all lower level themes, structured in a conceptual framework around the three key concepts of knowledge, situation, and motivation as described in "Situated social interactions in public places". Orthogonal to these concepts, three "place-related" design ideas of sharing place, indexing to place, and augmenting place were drawn, implemented and evaluated, as described in "Designing for situated social interactions in public places".

\section{Situated social interactions in public places}

The conceptual framework encapsulates a structured understanding of every day social interaction in the situation of a public place. It provides an understanding of the role of physical and social context in how people experience a physical

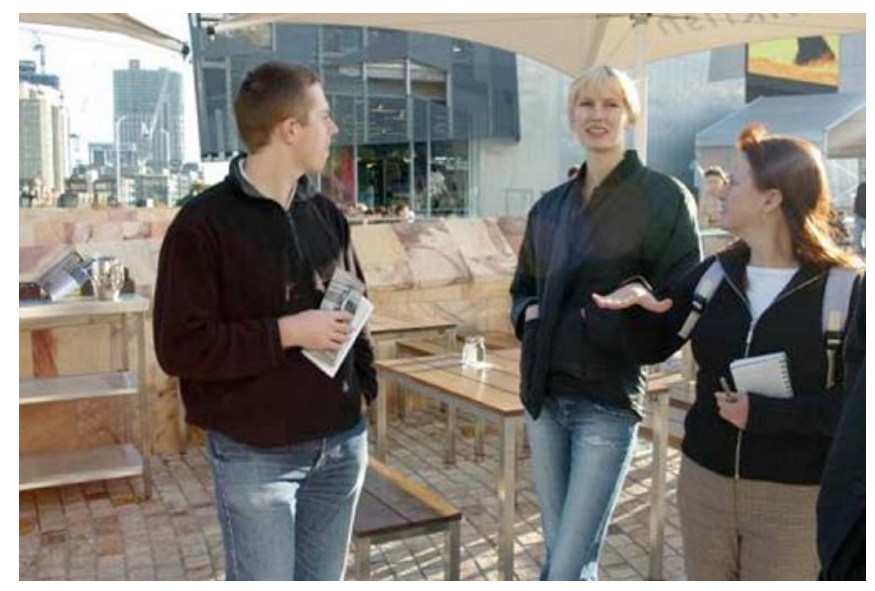

Figure 2. Contextual interview. 


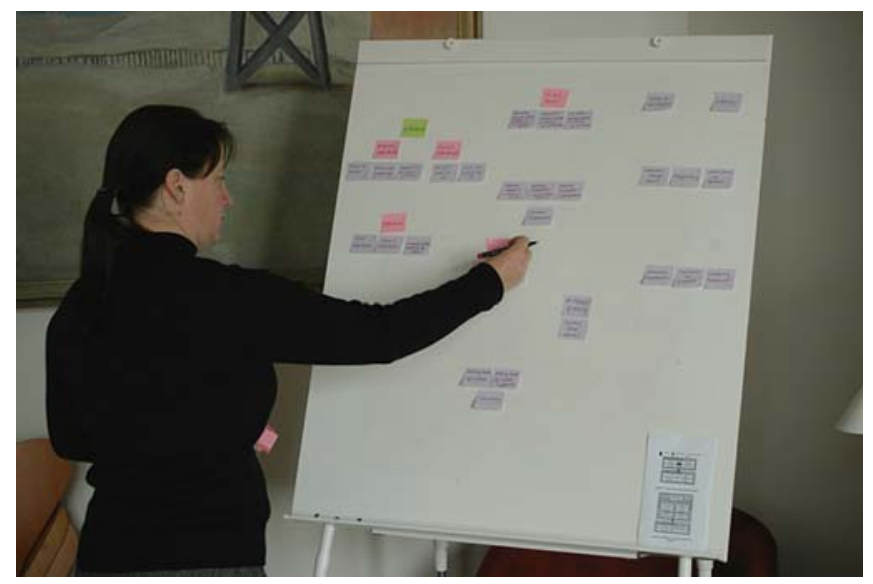

Figure 3. Affinity diagramming.

place and how they interact with each other while socialising, in the form of a qualitative story woven around three key concepts: knowledge, situation and motivation.

\subsection{Knowledge}

Knowledge is an important part of how we operate while socialising in an urban environment. When interacting in urban places people use their understanding of the world around them to make sense of things.

In the study, participants operated using the physical affordances (Norman 1990) of elements, for example, assuming steps with tall risers as being for sitting. They saw large open spaces as places for people to gather. If a space had a visual focal point then it was regarded as a good place for locating a special event or performance. Visible openings in facades indicated entrances, and architectural features such as low walls defined boundaries for sitting or walking and in this way confined activities. Participants drew on their history with that specific urban environment. Physical familiarity with a space meant that they approached familiar places using familiar paths, that is, the way that they "usually come". A familiar path was not perceived as the long way round, even if it was in terms of physical distance and they often assumed that others had the same familiar paths.

Participants also operated in public places using a set of social affordances. They looked to what other people were doing as cues for what to do in a place. Following crowds or people queuing was a way for them to decide where they might go. They looked at others to confirm what activities were acceptable in a place. Places where others were sitting made them feel they might sit there too. They read the presence of many people in an establishment as a recommendation that it was a good place to go. Participants expressed a desire to socialise where 
others were relaxing and enjoying themselves and were drawn into a place where they could see this happening from the outside. They also used social experience as a basis for selecting places to socialise with friends and their own past experience or shared group experience to index to past social events, for example "let's meet where we met last time". The impression of liking a place was based on successful past visits. Trying new places was based primarily on recommendations from friends or trusted media reviews. If they were socialising with a group of friends, they met in the place where they usually met with those particular friends.

\subsection{Situation}

Situation is an important aspect of sociality in urban space. When socialising the presence of both friends and strangers influences the way that people behave and move through urban place.

In the study, friends maintained their sense of "group" by the way that they physically located themselves in a public place. As they moved through space they often walked abreast, or single file in crowded situations, but always very much together. When they stopped they gathered in a circle to discuss options and excluded outsiders from the interaction.

Participants liked to be near others but not necessarily interacting directly with them. One participant called this "socialising by proximity" meaning that they wanted to be amongst others, often enjoying sharing a long table with several other groups in a place, but not feeling as if they had to talk directly to them. They liked to watch others, especially if they felt unobserved themselves. This generally meant being in an elevated position compared to the people they were watching or behind a low wall or plant box, to keep others at a distance. They mostly engaged in this activity when on their own.

Participants liked to wait for others in a place where they could see their friends arriving, specifically in a location that overlooked the entrance to a place, for example, at a table facing the door of a bar. The length of time that they had to wait affected the choice of meeting place. If their friend was going to be a long time (defined by participants as $30 \mathrm{~min}$ or more) they wanted an activity to do while waiting. If it was a short time (a few minutes) convenience to the meeting place was more important. Sitting outside at bars and cafes was perceived as more comfortable than waiting alone inside.

Setting influenced sociality. The presence of others and the types of people in a place influenced its acceptability. Participants expressed that they liked to socialise in places with similar types of people, i.e., age, dress, intentions. Environmental comfort was also important. Whether a place was sunny, sheltered, etc., influenced the choice of location to socialise or wait. Participants preferred sitting outside socialising in nice weather. They also preferred to sit in an elevated position with an interesting view out. The convenience of a place was 
also important. Participants preferred starting a "night out" in a location that had other activities they might like to do nearby.

Surroundings were an important part of situation and were often used as reference points. Participants indexed to things around them and to experiences shared with the friends they were with. They gave directions to a friend by referring to shared places and activities such as "next to the place we went last time where we sat in the sun". Participants also referred to visible elements, pointing to them or referring to generally known events or physical objects, including landmarks. For example, they would often use statements such as "through that opening", or index to landmarks in their surroundings, such as "it's near the big screen". Connecting stairs or pathways between physically separated spaces formed major transition points used in descriptions on how to get from one place to another.

\subsection{Motivation}

Reflection on current experience is part of socialising in a place. People try to size up the situation and like to get an overview of what is happening in a place. Before entering a place they stand back and familiarize with it and often pause before committing to a situation.

In the field, participants strived to make sense of things and places around them. Even if they had already decided to go to a familiar place, they would stand outside and review the menu before going in. Making sense of how things were organised was based on people's past experience with similar situations and by assessing the activities of others. Participants made very little use of signage, information kiosks or media screens in trying to do this sense making. Media screens while ostensibly informative were often regarded as decoration, something to make an environment more exciting. If they had a query, they usually asked a friend.

Participants gathered information about a place while socialising in it. Individuals required different levels of information for different activities. Those who required the most cursory level of information often set the pace of the group, others requiring more detail said they would only seek this depth of information when on their own. All participants wanted to know what was new in a place and if something special was happening.

In wayfinding, participants navigated by familiar paths and looked ahead for structures, objects and landmarks that they recognised and knew were near their destination. Participants discovered that urban spaces were dynamic, and paths were sometimes altered by the presence of crowds and temporary or new structures. In this situation, they avoided unfamiliar paths if they were not sure where they led, searching for the nearest familiar place and preferring to walk toward light rather than dark paths.

Extension of knowledge about a place often motivated social activity. Participants took part in exploration for the sake of it by wandering and browsing 
in a space. Sometimes they just wanted to know what was going on without any intention of joining activities. They enjoyed browsing as a group activity, allowing displays in shop windows to draw them in, and spent time negotiating what to do and where to go next.

\section{Designing for situated social interactions in public places}

Inquiring into the usefulness of the understanding represented by the conceptual framework for informing interaction design, we designed, implemented and evaluated a prototype system for fostering social connections "in place". Firstly, we conducted a 2-day design workshop to derive design ideas - or "design sensitivities" (Ciolfi and Bannon 2003) - for a context-aware mobile information system supporting sociality in the city. Following this, several iterations of paperprototyping (Snyder 2003) turned the most promising ideas into a high-fidelity paper prototype. Subsequently, we implemented the paper prototype as a functional web application running in Microsoft Pocket Internet Explorer on HP iPAQ h5550 using mySQL, PHP, pushlets and server-side applications for handling context-awareness and dynamic generation of maps and graphics. The final system keeps track of the user's location, their current activity and friends within close proximity. It also keeps a history of the user's visits to places around the city. The technical details of the prototype are described in Kjeldskov and Paay (2005). The prototype system was evaluated by studying peoples' use of it for approximately 1 hour in either a laboratory or while socialising at Federation Square. The evaluation participants were 20 established social pairs familiar with Federation Square (10 in the lab and 10 in the field), and the prototype was preloaded with details about the participant's history of social interactions at Federation Square, together as well as on their own or with other people, derived from a pre-evaluation questionnaire.

In this section we focus on describing three of the seven design ideas emerging from the fieldwork to illustrate the resulting prototype design, and highlight feedback from the evaluations. Each design idea was drawn directly from themes and categories in the conceptual framework:

Sharing place: recommendations based on history and context

Indexing to place: wayfinding referring to the familiar

Augmenting place: representing people and activities in proximity

\subsection{Sharing place: recommendations based on history and context}

Evidenced in the data by the way people make decisions about where to go, was the importance of people's past experiences in terms of their existing knowledge, history of visits, social experience with places, and their current social group. This was explored using a sketch to examine the relationship of experience between two people, A and B (Figure 4, left). Looking at the sketch from A's 

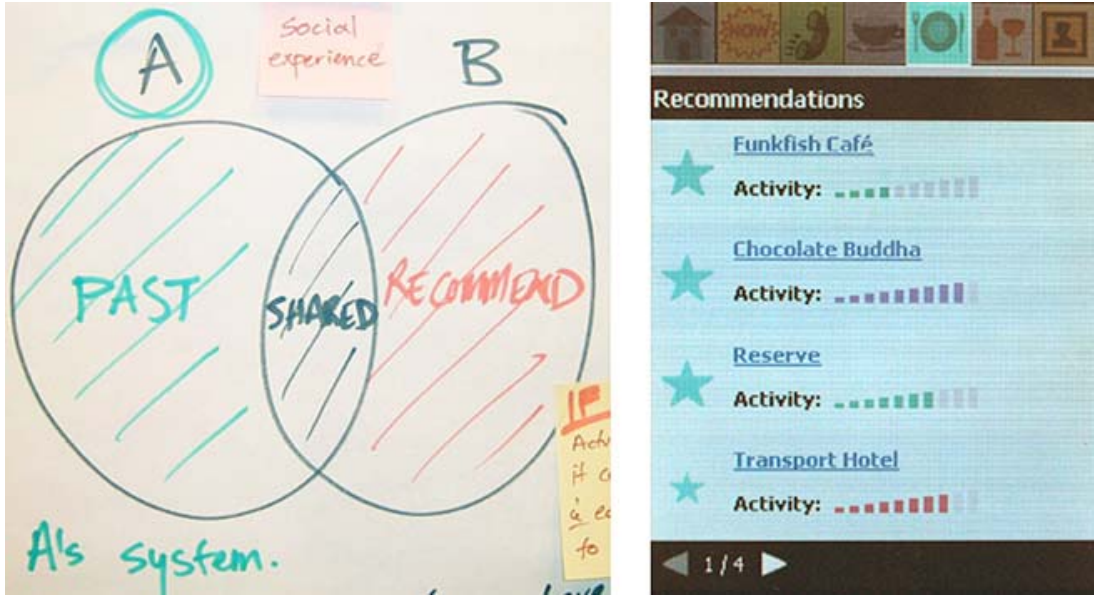

Figure 4. Design sketch: indexing to peoples' individual and shared histories, and corresponding prototype screen: ranked list of recommendations.

point of view, A has a past history which includes a number of familiar places. A subset of A's history is shared with B and represents shared experience which can be referred to through indexical relational descriptions such as "where we met last time". B also has a past history of familiar places that A has not been to. When A and $\mathrm{B}$ are socialising these places become recommendations from $\mathrm{B}$ for new places for A to go.

On the basis of the overall design idea of indexing content to the users' individual and shared histories, the prototype was designed to facilitate "sharing place" by ranking recommendations about places to go. When a member of a social group (the user) selects a specific activity on the device, for example, "having coffee", it presents a list of recommendations of places to go (Figure 4, right), ranked on the basis of the systems knowledge about the user's familiar places (where the user has been to before together with these friends), current social setting (places that people in the current social group have been to before but not together), the current environmental setting (how well the weather situation of past visits to a place fits the current conditions), and convenience (places within the vicinity of the social group). Each place has an associated "activity-meter" displaying the current patronage and primary activity to accommodate the finding that setting matters in relation to the presence and similar intentions of others in a place. This gives the social group a chance to pause before committing to an activity or a place.

Studying the use of this feature in the evaluation of the system, we found that people generally thought it was interesting to be able to share information about places they liked to go to and also be able to explore new places in a space through implicit recommendations from the friends they were with. However, they also expressed that they would like to have more control over the system's 
methods for ranking of places. On the interaction design level, we found that while people generally understood that the system adapted information to their location in space and to the places around them, they were surprised that the system also adapted to their social context (who they were with) and had to have this explained to them indicating that this design lacked the necessary interface cues for them to fully understand it.

\subsection{Indexing to place: wayfinding referring to the familiar}

The data collected shows that people seldom navigate by means of detailed maps and route descriptions when making their way around a space such as Federation Square as a part of a social group out on the town. Instead they use their history and especially physical familiarity with a space or place as well as physical affordances, such as visible places to enter and landmarks, to find their way around a space. They rely on simple indexing to their familiar places and prefer to follow their familiar paths from one place to another even if this may not be the most direct route. This finding was used to develop a sketch of the idea of basing wayfinding instructions on simple, indexical references to landmarks and familiar places with consideration to the user's history of familiar paths rather than the most direct route (Figure 5, left). In the prototype, the "Getting There" option displays information to the user about how to get to a destination from their current location based on references to places where they have been before, for example, "Chocolate Buddha is located next to ACMI Cinemas opposite Arintji" (Figure 5, right). If the destination is not in the vicinity of anything known by the user, the wayfinding descriptions direct the user to the familiar place or landmark closest to the destination and give detailed directions from there. The wayfinding directions are combined with photographs of places, landmarks and transition points providing information that takes into consideration what people already
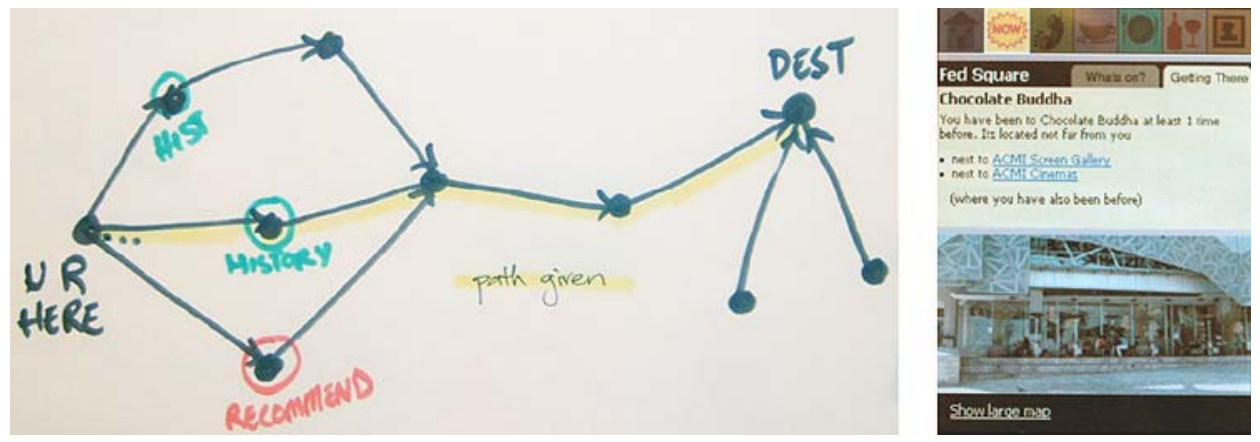

Figure 5. Design sketch: indexing wayfinding to familiar places and paths, and corresponding prototype screen: Indexical wayfinding directions. 
know about places around them, and acknowledges their ability to make sense of an unfamiliar place on the basis of a few simple cues to familiar elements.

Studying the use of this feature, we found that people were highly capable of making sense of sometimes very reduced and fragmented information when it related to places they already knew. People were good at matching up objects, structures and outlines in their physical surroundings to images on the screen. Using pictures as reference points for both familiar places and for significant structures and elements of the surrounding space helped "fill in the gaps" in the wayfinding instructions.

\subsection{Augmenting place: representing people and activities in proximity}

Another important observation made from our field study was the importance of knowing about the existence of other people in a space and what they are doing. The interaction between a social group and the co-inhabitants of a space is complex. It involves a certain level of interaction between the group and others, either by proximity or by watching. Observing where other people are gathering and what they are doing there helps in getting an overview of a place, making sense of what is happening and sizing up the situation, which are an important part of pausing before committing to enter a place. This finding was used to sketch and develop the idea of representing current activities of others within close proximity (Figure 6, left).

In the prototype, when the user selects "NOW" in the main menu it displays a small map of the user's immediate surroundings (Figure 6, right). On this map superimposed, dynamically updated coloured circles indicate the clustering and activities of people within proximity. The radius of the circles indicates the number of people at a place while the colour represents their primary current activity (e.g. purple shows people "having coffee"). The map also shows the
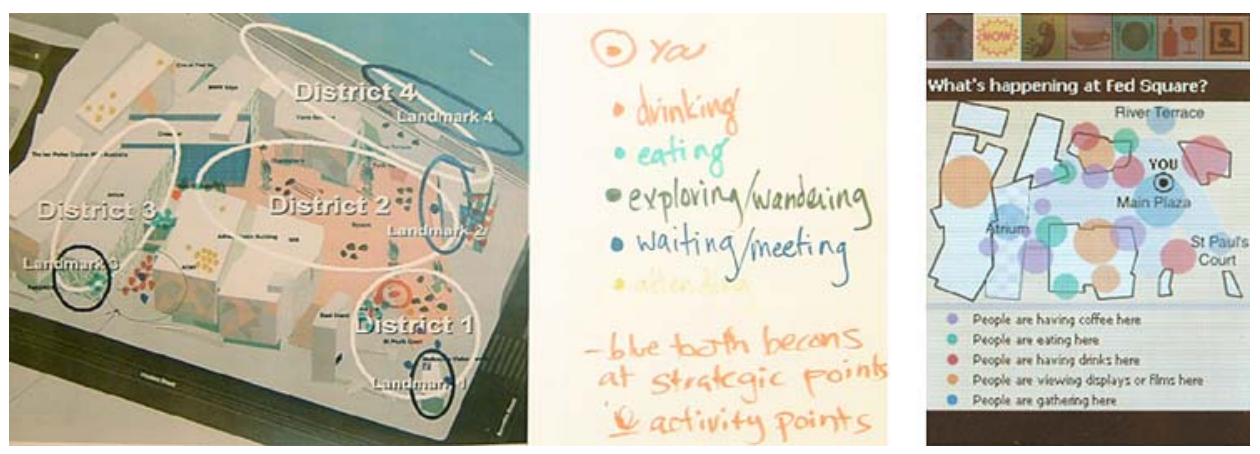

Figure 6. Design sketch: representing activities and people in proximity, and corresponding prototype screen: dynamic activity map of places nearby. 
location of the user. By clicking on the coloured circles the user can access more information about each place.

Studying the use of this feature, we found that people were fascinated with the idea of knowing about people, places, and activities in the space immediately surrounding them. This was perceived as being of great interest and value for getting an overview of a public place and for informing discussions among the group about what to do and where to go next. People happily made detailed assumptions about the presence and activities of other people in the places around them based on this relatively simple graphical representation.

\section{Conclusions}

We have presented a case study of human experience of a physical place providing an understanding of peoples' situated social interactions in public places of the city derived from a field study of small groups of friends socialising out on the town. Based on a grounded theory analysis of our findings we have presented a qualitative conceptual framework of situated social interactions in a public place, and illustrated how this conceptual framework informed the design of a mobile context-aware prototype for supporting sociality in the city. This was achieved by providing a place-based understanding of peoples' situated social interactions in an abstract form inspiring design rather than specifying system requirements. Finally, we have presented preliminary empirical findings about the interplay between technology, people and place.

The literature calls for extended understanding of the contexts of everyday activities (Agre 2001; Ciolfi 2004; Dourish 2001; Erickson 1993; McCullough 2004). This is especially important when designing ubiquitous and mobile computer systems pervading the places and social activities of daily life. We need to understand better the user's physical and social context, their situated social interactions (McCullough 2004), the role of human activity within the built environment (Ciolfi 2004) and the interplay between context and user actions (Dourish 2004).

Understanding how people behave in public places can be interpreted by considering their social and physical context, that is, the roles of others and their surrounding environment. The presence and activities of people in the built environment gives locations in space cultural and social meaning, transforming spaces into places. The history of interactions in a place, and the experience of similar situations in other places, all influence peoples' perception and understanding of a place. To be able to design mobile services for fostering social connections in place, their situated social interactions need to be understood in respect to the physical and social context in which they occur.

Applying the notion of place to the study of peoples' situated social interactions in the city provides a useful lens and conceptual foundation for generating such understanding about the interplay between people, activities and 
place, and for informing the design of new ubiquitous and mobile technologies "augmenting the city".

\section{Acknowledgements}

This research is supported by the Danish Technical Research Council (26-040026), the Smart Internet CRC, Australia, and The University of Melbourne's David Hay Award program. The authors thank everyone participating in the field study and prototype evaluations. We also thank Steve Howard and Bharat Dave for valuable input on the project.

\section{References}

Agre, P. (2001): Changing Places - Contexts of Awareness in Computing. Human-Computer Interaction, vol. 16, : pp. 177-192.

Beyer, H. and K.Holtzblatt (1998): Contextual Design - Defining Customer Centred Systems. Morgan Kaufmann: San Francisco.

Ciolfi, L. (2004): Understanding Spaces as Places: Extending Interaction Design Paradigms. Cognition Technology and Work, vol. 6, 1: pp. 37-40.

Ciolfi, L. and L.Bannon (2003): Learning from Museum Visits: Shaping Design SensitivitiesProceedings of HCI International 2003, Crete, Greece, June 22 to 27, 2003. Lawrence Erlbaum: London, pp. 63-67.

Donath, J. (1996): Inhabiting the Virtual City: The design of social environments for electronic communities. Unpublished Thesis, School of Architecture and Planning, Massachusetts Institute of Technology.

Dourish, P. (2001): Seeking a Foundation for Context-Aware Computing. Human-Computer Interaction, vol. 16, : pp. 229-241.

Dourish, P. (2004): What We Talk About When We Talk About Context. Personal and Ubiquitous Computing, vol. 8, 1: pp. 19-30.

Erickson, T. (1993): From Interface to Interplace: The Spatial Environment as a Medium for InteractionProceedings of Conference on Spatial Information Theory, COSIT'93, Elba Island, Italy, September 19 to 22, 1993. Springer: Berlin, pp. 391-405.

Gaver, B. (1996): Affordances for Interaction: The Social is Material for Design. Ecological Psychology, vol. 8, 2: pp. 111-129.

Grinter, R.E. and M.Eldridge (2001): y do tngrs luv 2 txt msg?Proceedings of the Seventh European Conference on Computer-Supported Cooperative Work ECSCW'01, Bonn, Germany, September 16 to 20, 2001. Kluwer: Dordrecht, pp. 219-238.

Harrison, S. and P.Dourish (1996): Re-placing Space: The Roles of Place and Space in Collaborative SystemsProceedings of Computer Supported Cooperative Work '96, Boston, Massachusetts, USA, November 16 to 20, 1996. ACM Press: Cambridge, MA, pp. 67-76.

Hillier, B. and V.Netto (2002): Society seen through the prism of space: outline of a theory of society and space. Urban Design International, vol. 7, : pp. 181-203.

Jones, Q., G.A.Sukeshini, L.Terveen and S.Whittaker (2004): People-to-People-to-GeographicalPlaces: The P3 Framework for Location-Based Community Systems. Computer Supported Cooperative Work, vol. 13, : pp. 249-282.

Kjeldskov, J. and J.Paay (2005): Just-for-Us: A Context-Aware Information System Facilitating SocialityProceedings of Mobile HCI 2005, Salzburg, Austria, September 19 to 22, 2005. ACM Press: New York, pp. 23-30. 
McCullough, M. (2004): Digital Ground - Architecture, Pervasive Computing, and Environmental Knowing. The MIT Press: Cambridge, Massachusetts.

Millen, D.R. (2000): Rapid ethnography: time deepening strategies for HCI field research Proceedings of DIS 2000, New York, USA, August 17 to 19, 2000. ACM Press: New York, pp. 280-286.

Mitchell, W. (1995): City of Bits: Space, Place and the Infobahn. The MIT Press: Cambridge, MA. Mitchell, W. (2003): ME++ The Cyborg Self and the Networked City. The MIT Press: Cambridge, MA.

Norman, D. (1990): The Design of Everyday Things. Basic Books: New York.

Rheingold, H. (2003): Smart Mobs. The Next Social Revolution. Perseus: Cambridge, MA.

Snyder, C. (2003): Paper Prototyping. The Fast and Easy Way to Design and Refine User Interfaces. Morgan Kaufmann: Amsterdam.

Strauss, A. and J.Corbin (1990): Basics of Qualitative Research. Sage: Newbury Park, California. 